\title{
Diagnosis of Faecal Schistosomiasis in the Context of its Epidemiology in Gabon: Molecular Tools as Alternative to Conventional Methods
}

\author{
Rodrigue Mintsa Nguema* ${ }^{* 1,2}$, Marielle K Bouyou Akotet ${ }^{2}$, Sevidzem Silas Lendzele ${ }^{1}$ and Jacques F \\ Mavoungou ${ }^{1}$ \\ ${ }^{1}$ Research Institute for Tropical Ecology, National Center for Scientific and Technological Research, Gabon \\ ${ }^{2}$ Department of Parasitology-Mycology, Faculty of Medicine, University of Health Sciences of Libreville, Gabon
}

*Corresponding author: Rodrigue Mintsa Nguema, PhD IRET/CENAREST, Gabon

\begin{tabular}{|c|c|}
\hline ARTICLE INFO & ABSTRACT \\
\hline Received: 幽 May 16, 2019 & Schistosomiasis is a parasitic disease caused by Schistosoma spp. In the Central Af- \\
\hline Published: May 22, 2019 & $\begin{array}{l}\text { rican context, faecal schistosomiasis is mainly caused by Schistosoma mansoni. In Gabon, } \\
\text { studies using the various para-clinical diagnostic methods showed some pitfalls like low }\end{array}$ \\
\hline $\begin{array}{l}\text { Citation: Rodrigue Mintsa Nguema, } \\
\text { Marielle K Bouyou Akotet, Sevidzem }\end{array}$ & 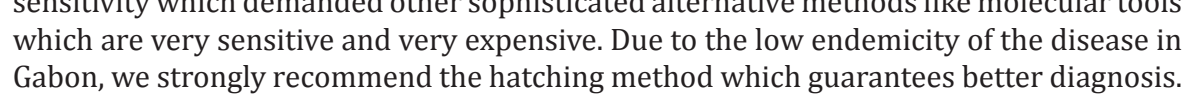 \\
\hline
\end{tabular}

Silas Lendzele, Jacques F Mavoungou.

Diagnosis of Faecal Schistosomiasis

in the Context of its Epidemiology

Keywords: Faeces; Schistosomes; Epidemiology; Molecular Tools; Conventional Methods

in Gabon: Molecular Tools as Alter-

native to Conventional Methods. Bi-

omed J Sci \& Tech Res 18(2)-2019.

BJSTR. MS.ID.003120.

\section{Introduction}

\section{A Brief Overview of the Epidemiology of Faecal Schisto- somiasis in Central Africa}

In Central Africa, faecal schistosomiasis is mainly caused by Schistosoma mansoni. Its wide distribution is associated with the presence of Biomphalaria, the intermediate snail host living in the fresh waters of Africa [1]. In Cameroon, S. mansoni was detected since 1959 in populations residing around the Olezoa fishponds in Yaounde, with an infestation rate of $64 \%$ [2]. It was also described in Nkolmébanga near Saa bordering the Sanaga in southern Cameroon [3] and Minkana in the Lekie Division [4]. In 1981, the Kosa and Dougué foci in the north of the Mandara mountains were highlighted [5]. Several urban and peri-urban areas are listed, such as Melen, which covers part of the border areas of the campus of the University of Yaoundé I [6,7]. Recent data from 63 of the 179 health districts of Cameroon indicate that infection with $S$. mansoni is the most frequent with an overall prevalence of 5.53\% [8]. In Congo, studies carried out in Brazzaville in 1963 and 1976 revealed that the infection rates were $22.1 \%$ in Konilon, $19 \%$ in Niari and less than $5 \%$ in Lekoumon, Bouenza, Pool, Plateau, Cuvette, Likouala and Sangha [9]. In the Central African Republic, reports indicated the existence of populations infected with $S$. mansoni in almost the entire territory. However, only the south-western region, comprising of the Sangha departments, can be considered as a low-risk area with an infection prevalence of less than $0.5 \%$ [10]. In Chad, the distribution of intestinal schistosomiasis is mainly associated with the Logone and Chari basins. Outside the valleys of the south-west, this parasite is present only in Abeche in the mountains of Ouaddaï. In addition to this major species, S. guneensis in the region of the Gulf of Guinea and S. intercalatum in the Kinshasa region, Democratic Republic of Congo, are also encountered at very low levels. These last two faecal schistosomes are transmitted by intermediate snail hosts of the genus Bulinus: Bulinus forskalii for S. guineensis and B. globosus for S. intercalatum. 


\section{Epidemiology of Faecal Schistosomiasis in Gabon}

In Gabon, faecal schistosomiasis is only caused by S. guineensis and was the first reported case of bilharziasis in the country [11]. To the best of our knowledge, there exist no published data on the local transmission of $S$. mansoni in Gabon despite its presence in other neighboring countries of Central Africa. Some cases were reported [12] but there was no evidence of the presence of this species in Gabon [13]. In 1995, a case of S. mansoni was diagnosed among patients diagnosed at the department of parasitologymycology of the Faculty of Medicine and Health Sciences of Libreville (FMSS). A case was diagnosed in a 14-year-old boy of Gabonese nationality who had always lived in Gabon. In 2009, a clinical case involved a girl complaining of abdominal pain (FMSS data). Coprological examinations (MIF concentration technique) showed the presence of $S$. mansoni eggs recognized through its characteristic lateral spur (unpublished data). Based on its public health importance, the distribution of faecal schistosomiasis in Gabon needs to be elucidated. A survey, carried out at Plaine Orety in Libreville, indicated the presence of 4 cases of $S$. mansoni from a total of 495 people analyzed [14]. Recently, a study reported that the northern and eastern health regions of Gabon were represented low transmission areas of faecal schistosomiasis [15].

These results raised the question of a possible underestimation of faecal schistosomiasis due to the techniques and protocols used for its diagnosis. Although Kato-Katz is a widely used and recommended method for the diagnosis of faecal schistosomiasis, its efficacy is very low in areas with very low endemicity. Due to its low sensitivity, it was necessary to move towards molecular diagnosis which is a credible alternative to the Kato-Katz method $[16,17]$. The present mini review aimed at assessing the prospective of some molecular protocols versus conventional methods for the diagnosis of faecal schistosomiasis in the epidemiological context in Gabon. Indeed, an accurate diagnosis of helminthiasis is the starting point for better treatment of patients and effective control. The lessons learned can improve on patient management through the use of effective diagnostic tools in epidemiological surveys.

\section{Conventional Methods}

The methiolate-iodine-formaldehyde concentration (MIF-C) and Kato-Katz methods have been extensively used in surveys in Gabon $[14,15,18]$. These techniques are widely used and recommended by the WHO for the diagnosis of schistosomiasis in endemic areas. The Kato-Katz for instance is based on the principle of searching for eggs of schistosomes under a microscope using a very small amount of stool (maximum $50 \mathrm{mg}$ ). The advantages of using this method include simplicity, accessibility and its low cost. The critical analysis of these techniques indicates that despite the advantages listed, it is highly specific and advisable only in areas with high endemicity and not in areas with low endemicity. In low endemic areas, the intensity of infection (number of egg per gram of stool) is generally low and the conventional techniques (Katokatz and MIF-C) underestimates the level of infection, because of the very small amount (50 $\mathrm{mg}$ ) of stool that it analyzes and despite the recommendations that strongly encourage the use of replicate analysis. Therefore, molecular tools can be an alternative to overcome these shortcomings

\section{Molecular methods}

\section{Protocol According to Verweij et al. (2001)}

The principle of this protocol is to amplify and demonstrate using PCR the presence of DNA of Schistosoma in a stool sample. Stool samples should be stored at $-70^{\circ} \mathrm{C}$ prior to genomic DNA extraction and PCR. The protocol is based on the extraction of schistosome DNA from a stool solution in $0.5 \mathrm{~g} / \mathrm{ml}$ of PBS buffer. The extraction is carried out using a Qiagen extraction kit (QIAamp Tissue Kit after treatment with 4\% PVPP (polyvinylpolypyrolidone) (Sigma, Steinheim, Germany) and a mixture of Sodium dodecyl Sulphate-Proteinase K [19]. It can be more specific than KatoKatz because PCR amplifications can be carried out with a very small amount of DNA, but it is much more expensive and more difficult to use because it can only be performed by very competent individuals in the domain of molecular biology who are acquainted to the reagents and equipment. It also has the disadvantage of not giving information on the intensity of the parasite.

\section{Protocol According to Pontes et al. (2003)}

It is based on the same principle of PCR amplification of schistosome DNA in a stool sample defined above. Stool samples should be frozen prior to usage. The protocol for DNA extraction uses $0.5 \mathrm{~g}$ of stool which is mixed with $1 \mathrm{ml}$ of distil water [19]. DNA extraction is not carried out using a Qiagen kit but following the ROSE protocol [20]. This protocol is less expensive and easier than the extraction protocol with the Qiagen kit. It can make better diagnosis than the Kato-Katz because it uses small amount of sample and significant genomic DNA copies can be gotten from very small amount of such stool samples. The disadvantages with this technique are the lack of equipment as well as competent individuals who can manipulate such equipment. Also, in an area of low endemicity, it is likely that the chances of having the eggs and consequently the DNA are not optimized from only $0.25 \mathrm{~g}$ of stool. This method does not give information on the intensity of the parasite.

\section{Protocol According to Ten Hove et al. (2008)}

It uses the same principle and the same steps defined in the protocol of Verweij et al. [19]. Here, the stool samples collected from subjects need to be processed by making a dilution of $0.25 \mathrm{~g} /$ ml using $70 \%$ ethanol within a $24 \mathrm{hrs}$ time frame and the PCR used is a real-time PCR [16]. The advantages, criticisms and disadvantages highlighted in the protocol of Verweij et al. [19] are also valid here. Unlike Verweij et al. [19], the PCR technique used here gives an idea of the amount of DNA and hence the intensity of infection. 


\section{The Hatching Technique}

The principle of the hatching method consists of filtering a stool sample with saline solution $(0.09 \%)$ in order to recover the eggs and hatch them to obtain miracidia through a sieve with fine mesh size. The stool can be stored in the refrigerator for $24 \mathrm{hrs}$. Briefly, a mouse parasitized by $S$. mansoni and conserved dead for three days at $4^{\circ} \mathrm{C}$ results in a liver with eggs that hatch and release miracidia (unpublished data). The protocol of the hatching technique uses the entire available stool sample, at least $10 \mathrm{~g}$ [21]. Any parasitologist can perform this method. This protocol is ideal for field use in endemic settings. The only disadvantage with this technique is that it is long and laborious as it takes 2 to 3 hrs on average just to filter a stool sample until hatching of the eggs and release of miracidia. This duration is necessary because it is required to give a real image i.e. twice the parasitic status of the sample of the stool analyzed and it equally allows for the identification of the eggs after filtration as well as in the identification of miracidia. In addition, eggs can be misplaced in the stool solution obtained after filtration, and the possibility of allowing them to hatch to give miracidia, which is more easily repairable, is an additional option for an optimal diagnosis. In this case, the confirmation of the species can be carried out using an additional biomolecular analysis on the miracidia obtained. In areas of low endemicity, this is the most credible way to have an accurate picture of the epidemiological situation. However, it is necessary to carry out a pilot study with the objective of evaluating the cost/ time and ease of execution of the results in order to validate on the need to invest in such a long protocol.

\section{The High-Resolution Melting (HRM) Analysis}

The HRM analysis is a technique that detects very small sequence variations from a nucleotide and is based on real-time PCR. It is based on the denaturation of the two strands of the DNA sequence by heating the latter following a temperature gradient. The denaturation temperature, repairable with the loss of the signal of the interacting agent (Syber green) active only on the double strand, is very specific and varies between two different sequences even of a single nucleotide. Today, it is a method of choice because it is rapid, specific, sensitive and effective, and allows us to answer specific questions concerning the interaction between some schistosome species in endemic settings [21].

\section{Pitfalls of the Diagnosis of Faecal Schistosomiasis in Gabon}

Diagnosis is based on the amount of stool sample to be analyzed and on the endemicity of the country. All parasitological techniques for the diagnosis of schistosomes are aimed at identifying the parasite (its eggs, its miracidia, and its DNA). It is therefore important to maximize the chances of detecting it. The first way to maximize these chances relies on the amount of stool to be examined. The major concern here is that the screening is carried out in areas with low parasitic load. The critical analysis of the different diagnostic techniques taught us some important lessons. If the conventional methods as the Kato-Katz underestimates the infection prevalence in a zone of low endemicity, it is because the parasites present in the stool examined (i.e. maximum $50 \mathrm{mg}$ of stool) is weak. The quantity of stool examined is multiplied by 10 in proportions indicated by Pontes et al. [16], i.e. $0.5 \mathrm{~g}$ and by 200 in the proportions indicated for hatching i.e. about $10 \mathrm{~g}$. It is therefore very useful to adapt the diagnostic technique to the field context, because the results highly depend on the amount of stool analyzed and the endemicity of the study area. The results obtained in Libreville [14] and in the northern and eastern health regions of Gabon [15] using the Kato-Katz method indicated that Gabon had a low prevalence and low intensity for S. mansoni. The review of the critical analysis of parasitological techniques used for the diagnosis of bilharziasis reveals that those that are widely used, notably Kato-Katz, were less sensitive in areas of low endemicity, like in the case of Gabon [15].

The hatching technique is a credible alternative to the latter, since it maximizes the chances of an optimal diagnosis by multiplying them by a factor of 200 compared to the Kato-Katz. Its guarantee is thanks to its approach and its principle of double observation of the parasite i.e. first on eggs and a second on miracidia. This technique does not only offer the possibility of diagnosis but also the possibility of studying the transmission dynamics on a small scale of the individuals or the possibility of extracting the strain necessary for analysis in different aspects in the laboratory. Thus, the hatching technique can make it possible to approach in a more integrated way the studies on schistosomiasis in Gabon. In Gabon, several species of Schistosoma prevail notably $S$. haematobium, $S$. guneensis and probable hybrids [22] and S. mansoni [14,15]. The obvious concern will be to distinguish the species and to show their hybrids. However, this can be carried out using the HRM technique. Indeed, it is known that the use of simple morphology or morphometry of the eggs as well as their localization is not enough to differentiate certain Schistosoma spp. [18]. The possibility of using the HRM gives some hope for the clarification of the possible interactions between the different species present in Gabon, insofar as the results will instruct decision-makers to effectively control this parasite. The use of the HRM technique to answer multiple questions about the epidemiology of schistosomiasis in Gabon may be possible through our collaboration with the laboratory of Perpignan whose expertise on this topic is well known.

In the context of low endemicity like ours, we strongly recommend the hatching method which guarantees a better diagnosis and offers the possibility of responding to many questions, in combination with the HRM in the context of the epidemiology of schistosomiasis in Gabon. The only inconvenience of these techniques is that they are very expensive and difficult to perform on a large scale or under field conditions [23]. DNA extraction is a key procedure, but it can be a methodological bottleneck in molecular diagnostic assays since preservation and initial quantity of stool to be examined directly affects the yield and quality of genomic DNA and thus the PCR results. It is often 
the most expensive part of DNA-based diagnosis, particularly when using commercially available extraction kits.

\section{References}

1. Brown DS (1994) Freshwater Snails of Africa and their Medical Importance. ( $2^{\text {nd }}$ Edition), Taylor \& Francis, London.

2. Landon A (1961) Aperçu sur la bilharziose au Cameroun. Institut Pasteur Yaoundé p. 1-11.

3. Lamberton A, Ravinet L, Carrié J (1978) Le foyer de bilharziose intestinale mixe de Nkolmébanga. Epidémiologie essai de control OCEAC Yaoundé 1-15.

4. Ripert C, Ambroise Thomas P, Rousselle Sauer C (1978) Etude épidémiologique des foyers de schistosomose à S. mansoni de Minkama et Nalassi (département de la Lékié, Cameroun). Rev Epidémiol Sant Pub 26: $403-412$

5. Luncas JJ (1981) Etude épidémiologique des helminthiases intestinales dans la région de Kosa (monts Mandara, Nord-Cameroun). Thèse Médecine Bordeaux II p. 86.

6. Deschiens R, Delas A, Ngalle ES, Pointier A (1968) La répartition géographique des bilharzioses humaines au Cameroun. Bull Soc Pathol Ex 61: 772-778.

7. Wandji NR (1976) Contribution à l'étude épidémiologique de la bilharziose à Schistosoma mansoni dans les étangs de Mélen à Yaoundé. Thèse Médecine Université de Yaoundé p. 96.

8. Tchuem Tchuente LA, Kamwa Ngassam RI, Sumo L, Ngassam P, Dongmo Noumedem C, et al. (2012) Mapping of schistosomiasis and soil-transmitted helminthiasis in the regions of centre, East and West Cameroon. PLoS Negl Trop Dis 6(3): 15-53.

9. Itoua N Gaporo A, Coulm J (1978) La bilharziose intestinale en République populaire du Congo: considérations épidémiologiques à partir des cas déclarés entre 1952 et 1976. Med Trop 38: 537-546.

10. Saugrain J (1967) La bilharziose en République centrafricaine. Med Trop 27: 156-166.

11. 2 Clapier PN 1923 Schistosomum haematobium à Libreville. Bilharziose autochtone, bilharziose importée. Bull Soc Pathol Ex 47: 531-534.

12. Deschiens R (1952) Le problème sanitaire des bilharzioses dans les territoires de l'Union Française. Masson, Paris, pp. 100.

13. Mc Cullough FS (1975) Les Schistosomiases en République du Gabon. Rapport de mission 4-24 juin et 11octobre - 27 novembre 1975. OMS, Brazzaville p. 1-65.

\section{ISSN: 2574-1241}

DOI: 10.26717/BJSTR.2019.18.003120

Rodrigue Mintsa Nguema. Biomed J Sci \& Tech Res

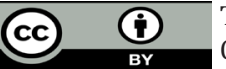

This work is licensed under Creative

Commons Attribution 4.0 License

Submission Link: https://biomedres.us/submit-manuscript.php
14. Mintsa Nguema R, Mve Ondo B, Mabika Mamfoumbi M, Koumba AA, Bouyou Akotet M K, et al. (2018) Recent Examination for Assessing Epidemiological Status of Schistosoma Mansoni in Plaine Orety, Urban Area of Libreville, Gabon, Central Africa. Cent Afr J Pub Health 4(3): 8185.

15. Mintsa Nguema R, Mavoungou JF, Mengue Me Ngou Milama, Mabicka Mamfoumbi M, Koumba AA et al. (2018) Baseline Mapping of Schistosomiasis and Soil Transmitted Helminthiasis in the Northern and Eastern Health Regions of Gabon, Central Africa: Recommendations for Preventive Chemotherapy. Trop Med.Infect Dis 3(4): 119.

16. Pontes LA, Oliveira MC, Katz N, Dias-Neto E, Rabello A (2003) Comparison of a polymerase chain reaction and the Kato-Katz technique for diagnosing infection with Schistosoma mansoni. Am J Trop Med Hyg 68(6): 652-656.

17. Ten Hove RJ, Verweij JJ, Vereecken K, Polman K, Dieye L, et al. (2008) Multiplex real-time PCR for the detection and quantification of Schistosoma mansoni and S. haematobium infection in stool samples collected in northern Senegal. Trans R Soc Trop Med Hyg 102(2): 179185.

18. Mintsa Nguema R, Mengue Ngou Milama K, Kombila M, Richard Lenoble D, Tisseyre P et al. (2010) Morphometric and molecular characterizations of schistosome populations in Estuaire province Gabon. J Helminthol 84(1): 81-85.

19. Verweij JJ, Pit DS, van Lieshout L, Baeta SM, Dery GD et al. (2001) Determining the prevalence of Oesophagostomum bifurcum and Necator americanus infections using specific PCR amplification of DNA from faecal samples. Trop Med Int Health 6(9): 726-731.

20. Steiner JJ, Poklemba CJ, Fjellstrom RG, Elliott LF (1995) A rapid one-tube genomic DNA extraction process for PCR and RAPD analyses. Nucleic Acids Res 23(13): 2569-2570.

21. Moné H, Minguez S, Ibikounlé M, Allienne JF, Massougbodji A, Mouahid G (2012) Natural interactions between S. haematobium and S. guineensis in the Republic of Benin.

22. Richard Lenoble D, Kombila M, Duong TH, Gendrel D (1993) Bilharziose à Schistosoma intercalatum, bilharziose récente et oubliée. Rev Prat 43: 432-439.

23. Jurberg AD, De OliveiraAA, Lenzi HL, Coelho PMZ (2008) A new miracidia hatching device for diagnosing schistosomiasis. Mem Inst Oswaldo Cruz 103: $112-114$

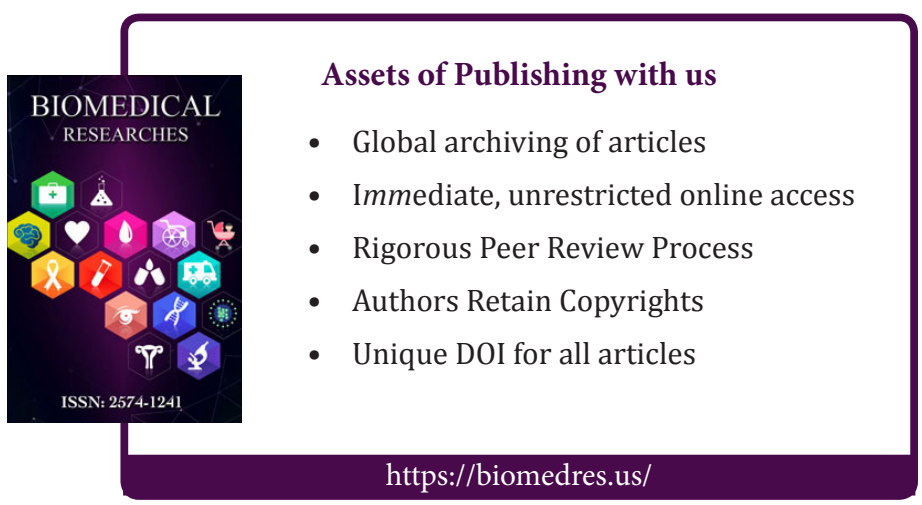

Copyright@ Rodrigue Mintsa Nguema | Biomed J Sci \& Tech Res| BJSTR. MS.ID.003120. 